\title{
Major Axis Internal Diameter at End Ventricular Diastole
}

National Cancer Institute

\section{Source}

National Cancer Institute. Major Axis Internal Diameter at End Ventricular Diastole. NCI

Thesaurus. Code C139059.

The internal diameter of a cardiovascular structure measured along its major axis at end ventricular diastole. 